\title{
Scale and Skill in Mutual Fund Management: Evidence from Norway
}

\author{
Markus Snøve Høiberg (iD $* 1$ \\ 1 Oslo Business School, Oslo Metropolitan University Norway \\ * Corresponding author: markus.snove.hoiberg@klp.no
}

Article History

Received 2020-04-02

Revised 2020-05-20

Accepted 2020-05-20

Published 2020-06-01

\section{Keywords}

Mutual fund performance,

Mutual fund scale,

Managerial skill,

Economies of scale

\section{How to cite?}

Hoiberg, M. S. (2020). Scale and Skill in Mutual Fund Management: Evidence from

Norway. SEISENSE Journal of

Management, 3(4), 1-20.

doi:10.33215/sjom.v3i4.351

\begin{abstract}
Using a sample free of survivorship bias and several risk-adjusted performance benchmarks to identify effects of scale on mutual fund performance in the Norwegian market, I find mixed evidence that both large and small funds underperform as against the middle-sized funds in the period 2005-2018. Controlling for relevant factors in panel data regressions, I find that, on average, performance worsens with an increase in size while giving support to initial findings of nonlinearity. The relationship is most robust after 2013 and seems to be affected by competition in the market as well as fund inflows. I do not find any empirical evidence to support the liquidity hypothesis.
\end{abstract}




\section{Introduction}

The Norwegian Mutual Fund industry has been growing at remarkable rates since the financial crisis of 2008 due to low-interest rates, new pension regulations, and increased availability and knowledge (VFF, 2018). This raises the question of how stakeholders adapt to the increases in scale and should be of particular concern for investors trying to pick the best performing mutual funds. This study provides the first evidence to my knowledge of how the size of a Norwegian mutual fund's asset base affects future performance through several risk-adjusted measures.

Active mutual funds are found to underperform passive strategies after costs on average, and performance is not persistent over time (Carhart, 1997; Fama \& French, 2010; Jensen, 1968). Nevertheless, investors choose to trust managers in allocating their assets. This paradox has puzzled practitioners and researchers alike for years, bringing mainly two questions: Why do active funds underperform their benchmarks? And why do investors still choose them? This study aims to increase understanding by answering the following two questions: Does the size of a fund's asset base affect risk-adjusted performance among Norwegian mutual funds investing in Norwegian equities? Are there any factors affecting the relationship between size and performance?

Many authors have contributed to developing some consensus on the role of fund size. Studies on funds in the US mainly show that fund performance worsens with size due to increased trading costs from liquidity issues and price movement (J. Chen, Hong, Huang, \& Kubik, 2004; Pástor, Stambaugh, \& Taylor, 2015; Perold \& Robert S. Salomon, 1991). However, the relationship is nonlinear as performance increase with size due to better resources, before decreasing as funds experience higher transaction costs, more attention, and administrative stress (Indro, Jiang, Hu, \& Lee, 1999). A cross-sectional study compares findings in the US to 26 other countries spanning from 1997-2007 ((Ferreira, Keswani, Miguel, Ramos, \& Finance, 2012). They find that the diminishing return to scale is not universally true outside the US, although the results are aggregated and therefore makes it hard to conclude. There are some studies on the performance of Norwegian mutual funds, however to the best of my knowledge, none have specifically investigated the size-performance relationship. At the end of 2018, around 240 companies were listed in Norway, having a market capitalization of about USD 267 billion. As fewer stocks make it harder to diversify, I expect liquidity to be a bigger problem in Norway than in the US, possibly translating into a stronger negative size-performance relationship. Factors such as the size of the mutual fund industry and the concentration of its competitors are also expected to affect performance. With more (less) money chasing mispriced assets, a higher (lower) price pressure is to be expected, although it might also bring positive incentives to perform. It might also be that the size of the fund's owning company plays a role as more prominent families have more resources and organizational possibilities. Financial intermediaries are introducing success fees, which makes identification of drivers behind the performance of increased importance both for managers and investors. This study contributes to the body of knowledge by identifying factors that should be considered by all participants and to provide more detailed insights into markets outside the US.

\section{Theoretical Framework}

One of the first attempts to explain expected returns about risk is the Capital Asset Pricing Model (CAPM) (Sharpe, 1964; Treynor, 1962). Assuming that investors have homogenous expectations and are trying to maximize returns for a given variance or to minimize the variance for a given return, the CAPM (Equation 1) postulates that the expected return for an asset less the risk-free rate will be equal to the market risk premium.

$$
\mathrm{E}\left[r_{i}\right]-r_{f}=\beta_{i}\left(\mathrm{E}\left[r_{m}\right]-r_{f}\right)
$$

The only risk factor in the model is the variance of the market, so the abnormal returns of the funds obtained by eliminating the market risk will be from the mispricing of assets in the market or other risk factors that funds 
are exposed to. In addition to the market risk premium, researchers included the size factor SMB (Small-MinusBig) and the value factor HML (High-Minus-Low) as well as the intercept term alpha (a) (Fama \& French, 1993; Ross, 1976). Studying the alpha will be of interest in this study as it represents a funds' performance over the expected return estimated by the regression and its risk factors. The model was extended by introducing a momentum factor to adjust for an asset's tendency to continue rising if it is going up and continue declining if it is going down (Carhart, 1997).

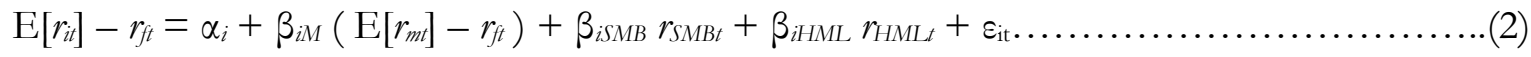

$$
\begin{aligned}
& \mathrm{E}\left[r_{i t}\right]-r_{f t}=\alpha_{i}+\beta_{i M}\left(\mathrm{E}\left[r_{m t}\right]-r_{f t}\right)+\beta_{i S M B} r_{S M B t}+\beta_{i H M L} r_{H M L t}+\beta_{i M O M} r_{M O M t}+\varepsilon_{\mathrm{it}} \ldots \ldots \ldots \ldots \ldots \ldots \text { (3) }
\end{aligned}
$$

Where rit is the portfolio return in month $\mathrm{t}$, and $\mathrm{rft}$ is the risk-free rate in month $\mathrm{t}$, ai is the intercept term which represents the performance not explained by the other factors, ( $\mathrm{rmt}-\mathrm{rft}$ ) is the excessive market return, and SMB, HML, and MOM are size factor, book-to-market factor, and Carhart-momentum factor respectively.

Later on, two factors are added, namely profitability and investment (Fama \& French, 2015), improving predictability, although it does bring some problems. The extended five-factor model fails to capture the low average returns of small stocks fully, and the investment factor is shown to be redundant in Europe and Japan (Fama \& French, 2017). For this study, the dependent variable is net fund returns adjusted for risk using three different approaches: a three-factor model, a four-factor model, and a benchmark adjusted return variable. I do not use the five-factor model for my purpose as smaller stocks account for a big part of the Norwegian market, and one of the factors, i.e. investment, is shown to be redundant in Europe. The fund size is my independent variable, and I use eight different controls.

Table 1 - The variables and their calculation

\begin{tabular}{|c|c|c|}
\hline Variables & Model Name & Calculation \\
\hline \multicolumn{3}{|l|}{ Dependent Variables } \\
\hline \multirow[t]{3}{*}{ Excess Return } & XRET3 & $\begin{array}{l}\text { Fund return - (Estimated returns from } 12 \text { months rolling window } \\
\text { of Three-Factor Model) }\end{array}$ \\
\hline & XRET4 & $\begin{array}{l}\text { Fund return - (Estimated returns from } 12 \text { months rolling window } \\
\text { of Four Factor Model) }\end{array}$ \\
\hline & XRETM & Fund return - Benchmark return \\
\hline \multicolumn{3}{|c|}{ Independent Variables } \\
\hline Fund Size & FDS & Log of the size of fund AUM at time $t-1$ \\
\hline \multicolumn{3}{|l|}{ Control Variables } \\
\hline Fund Age & AGE & Log of the age of the fund \\
\hline Expense Ratio & ER & Total Expense Ratio \\
\hline Family Size & FAS & Log of the size of fund family at time $t-1$ \\
\hline Industry Size & IND & Log of the size of fund industry at time $t-1$ \\
\hline Concentration & $\mathrm{CON}$ & 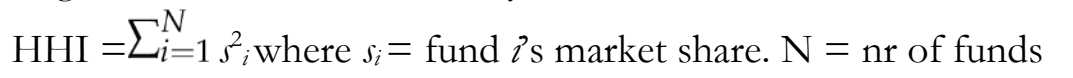 \\
\hline Mutual Fund Index & MFI & Dummy; 1 if TR Mutual Fund Index given as benchmark index \\
\hline Small Cap Index & SCI & Dummy; 1 if TR Small Cap Index given as benchmark index \\
\hline Manager History & $\mathrm{MH}$ & Dummy; 1 if change in management team at month $t-1$ \\
\hline Flow & FLO & {$\left[T N A_{t}-T N A_{t-1} * R_{t}\right] / T N A_{t-1}$} \\
\hline
\end{tabular}




\section{Data and Methodology}

To examine the effect of fund size on performance, I obtained the data from Thomson Reuter's Lipper and Datastream databases and Morningstar. The study includes monthly observations for 49 actively managed mutual funds with a Norwegian equity focus and spanning the period from January 2005 to December 2018. The asset universe is restricted to active mutual funds registered for sale in Norway with the Lipper Database classification of Equity Norway. These are funds with a primary focus on the Norwegian market and at least 80 percent of their assets invested in Norwegian equities, leaving some room for cash holdings. This excludes bond funds and other non-equity funds as well as index funds. All funds follow the European Union UCITS directives for investor protection which states that funds need to hold at least 16 different equities to ensure diversification and follow the 5/10/40 rule specifying a maximum of $10 \%$ of a fund's net asset may be invested in a single asset and that investments of more than 5\% with a single issuer may not make up more than $40 \%$ of the whole portfolio (EuropeanParliament, 2014). To avoid survivorship bias, this study includes liquidated and merged funds for the periods for which they were active. This could only be done by using multiple databases as inactive funds did not have information about Total Net Assets (TNA) in the Lipper database. Utilizing an additional source, Morningstar made it possible to compare the data in the two databases, which gives added certainty to the quality of the data. No significant differences were found neither in TNA nor Net Asset Value (NAV) between the databases. Morningstar also provides additional relevant aspects to the dataset, such as manager history and a Morningstar fund category, which helps to classify the strategy of the fund. The sample starts in 2005, as this is the earliest reported monthly observations of TNA.

A fund may enter the dataset several times as the database reports different share classes for the same fund. Assuming that managers make decisions for the fund in its entirety and care less about the size of each class, classes of a fund are merged into one representative. TNA is summarized, and one of the classes' NAV is chosen to represent the fund, effectively making sure that each fund is represented only once. NAV is reported after costs and might, therefore, vary for different classes as institutional investors usually pay less than private investors. As every fund does not have institutional classes, the most expensive class is chosen to have comparable returns across funds. As a new class is introduced, a significant increase in the merged fund's TNA usually appears as it is launched with rather big investors. This might be a weakness in the data, but overall it may contribute to random errors, and it should not significantly affect performance the next month.

In the estimation of fund's factor loadings, returns over the risk-free rate are used. I used monthly averages of the nominal Norwegian Interbank Offered Rate (NIBOR), a commonly used proxy for the risk-free return in the Norwegian market. I obtained this data from Norges Banks' webpages for the period before 2013 (Bank, 2019) and from the Oslo Stock Exchange for the period after 2013 (Børs, 2018). As both sources link to each other for their respective periods, it is assumed that the data is calculated equally and can be combined to span the whole period.

Three and Four-Factor regressions are estimated from available NAV-data starting in 2004 as twelve months rolling averages to account for changes in risk exposure through time. Factor loadings from the regressions are multiplied with real factor returns every given month and express estimated return. Deducting this from the actual return gives the risk-adjusted excessive return and the dependent variables, XRET3 and XRET4. From the histograms and Q-Q plots in Figure 1, there seems to be a negative skewness in the Three-Factor Model, while the Four Factor Model seems to be closer to a normal distribution. A Shapiro-Wilk test for normality Shapiro and Wilk (1965) gives a p-value of 0.2567 and 0.2478 for the Three and Four Factor Model. These are both above the critical value of 0.05 , indicating a normal distribution. 


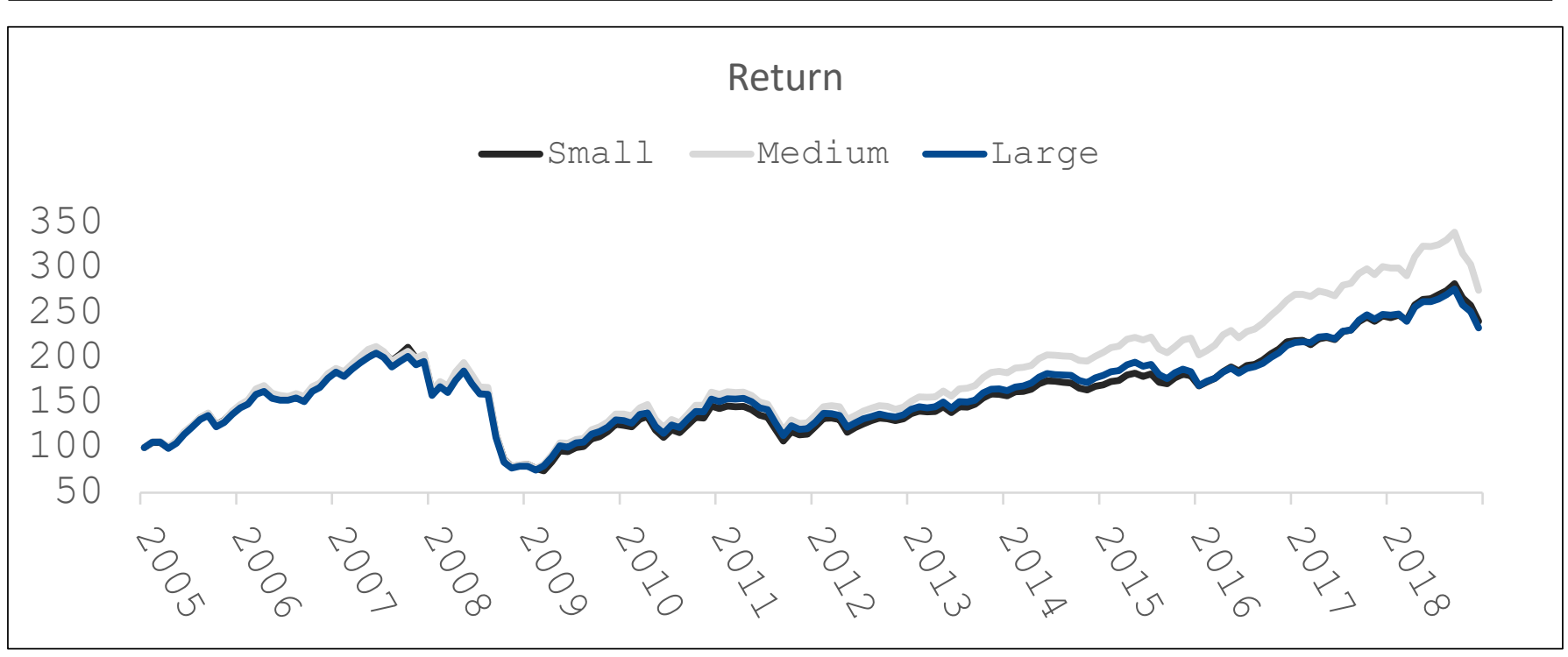

Figure 1 - Fund Groups Absolute Return

The third dependent variable (EXCRETM) is a benchmark-adjusted return, where the fund monthly net return is subtracted from the return on the fund's benchmark designated by the Thomson Reuters Lipper database. Three benchmarks are given, namely OSE Mutual Fund TR, OSE Benchmark TR, and OSE Small Cap Index TR. I summarize statistics for the three dependent variables in Table 2.

Table 2 - Summary statistics of dependent variables

\begin{tabular}{|c|c|c|c|c|c|c|}
\hline \multicolumn{7}{|c|}{ Panel A: Three-Factor Model } \\
\hline & Alpha & Rm-Rf & SMB & HML & MOM & adj. $\mathrm{R}^{2}$ \\
\hline Small & -0.0003 & 0.918 & 0.115 & 0.003 & & 0.827 \\
\hline Medium & 0.0005 & 0.992 & 0.167 & 0.016 & & 0.905 \\
\hline Large & -0.0002 & 0.966 & 0.114 & -0.001 & & 0.953 \\
\hline \multicolumn{7}{|c|}{ Panel B: Four Factor Model } \\
\hline Small & -0.0002 & 0.899 & 0.106 & -0.007 & -0.028 & 0.825 \\
\hline Medium & 0.0004 & 0.962 & 0.153 & 0.004 & -0.006 & 0.910 \\
\hline Large & 0.0000 & 0.949 & 0.110 & -0.007 & -0.026 & 0.953 \\
\hline \multicolumn{7}{|c|}{ Panel C: Benchmark-adjusted Monthly Return } \\
\hline Small & & $0.0009^{\circ}$ & & & & \\
\hline Medium & & 0.0013 & & & & \\
\hline Large & & -0.0001 & & & & \\
\hline
\end{tabular}

Note: The table reports average factor loadings for the three fund groups. Alpha is the constant derived from the regressions, $\mathrm{Rm}-$ $\mathrm{Rf}$ is the market return in excess of the risk-free rate, SMB is the size factor (Small Minus Big), HML is the book-to-market factor (High Minus Low), and MOM is the momentum factor.

The Three-Factor Model produces marginally more significant differences in alpha values between the groups than the Four Factor Model. Market return over the risk-free rate is the most influential factor for all groups in both models, describing most of the variation in fund return. It is most reliable for the medium-sized funds, hinting that smaller and bigger funds have less systematic risk. SMB and HML account for less of the variation in fund return. Including the MOM factor only marginally reduce loadings on the other factors. Including the momentum variable in the Four Factor Model does not seem to improve adjusted $\mathrm{R}^{2}$. Both models seem to explain most of the variation for all funds. 
The dataset is unbalanced, and hence I apply pooled regressions and fixed-effects techniques using the following specification.

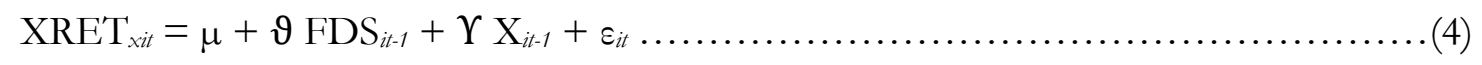

where $\mathrm{XRET}_{\text {xit }}$ is the return of fund $\mathrm{i}$ in month $\mathrm{t}$ risk-adjusted by three various performance benchmarks, $\mu$ is a constant (OLS), FDS ${ }_{i t-1}$ is the log of fund i's Assets Under Management (AUM) at month t-1, and $\mathrm{X}_{i t-1}$ are relevant to control variables in month $\mathrm{t}-1, \varepsilon_{i t}$ is the error term uncorrelated with all other independent variables, and $\vartheta$ is the main coefficient of interest as it captures the relationship between fund size and performance, controlling for the other variables.

The relationship under investigation is a challenge to estimate since the size is not randomly decided. While pooling the data assumes that the average values of the variables and the relationships between them are constant over time and across all the cross-sectional units, the skill of the fund manager impacts both the dependent variable performance and the independent variable size. Larger funds have better means to attract better managers who again attract more investors to the fund. As skill is unobservable, estimating a pooled OLS panel regression will then make room for an omitted variable bias with the same size as the effect of skill on performance times the slope of skill on fund size (Pástor et al., 2015). In other words, if skilled managers manage bigger funds, disadvantages with scaling might be hidden. J. Chen et al. (2004) argue that a fixed-effects model makes for a regression-to-the-mean bias. A fund that experiences a period of lucky performance will experience an increase in fund size. When performance regresses to the mean, a spurious conclusion will be made stating that an increase in fund size is associated with a decrease in fund returns. This is a negative bias which will lead to a more negative relationship between size and performance than it is. A clear disadvantage of using a fixedeffect model is that it excludes variables that might affect it but do not vary over time. For my dataset, the fund's benchmark index will be excluded as it is assumed to be the same through time. The expense ratio will also be excluded due to the same reason. In the following Table 3, I present the summary statistics of all the variables included in my models (Equation 4). By computing pooled regressions and fixed effects models on the panel data, I get six models with three different dependent variables regressed on lagged fund characteristics.

Table 3 - Summary statistics of all variables

\begin{tabular}{lcrrrrr}
\hline Variables & $\mathbf{N}$ & Mean & St. Dev. & Min & Max & VIF \\
\hline FDS & 6194 & 8.812 & 0.672 & 6.700 & 10.439 & 1.488 \\
AGE & 6194 & 1.115 & 0.300 & 0.000 & 1.681 & 1.364 \\
ER & 6194 & 0.016 & 0.004 & 0.002 & 0.025 & 1.102 \\
FAS & 6194 & 10.089 & 0.917 & 0.000 & 11.564 & 1.602 \\
IND & 6194 & 11.709 & 0.267 & 11.025 & 12.124 & 1.171 \\
CON & 6194 & 0.082 & 0.009 & 0.068 & 0.107 & 1.073 \\
MFI & 6194 & 0.160 & 0.367 & 0 & 1 & 1.188 \\
SCI & 6194 & 0.073 & 0.260 & 0 & 1 & 1.124 \\
MH & 6194 & 0.019 & 0.135 & 0 & 1 & 1.004 \\
FLO & 6194 & 0.010 & 0.166 & -0.966 & 9.516 & 1.009 \\
\hline
\end{tabular}

Note: The table presents descriptive statistics for the explanatory and control variables. The table also presents the Variation Inflation Factor.

\section{Group Performance}

In order to get a better understanding of the data and to see how funds of various sizes perform in different time periods, funds are divided into three groups for every month they appear in the dataset. Summary statistics for group sizes can be seen in Table 4. Funds can move between groups through time, but at any given month, the active funds at that time are divided in the 0,33 and 0,66 percentiles, which makes for three equal groups 
every month. With funds being divided into groups for every month in the period make it possible to compare the performance of the groups. Calculated returns net of cost can be seen in Figure 2. Medium-sized groups seem to have outperformed Small and Large, especially after the financial crisis. The average monthly return is highest for Medium-sized funds, but at the same time, so is the standard deviation of returns. To get a fair picture of the performance, I account for the risk taken by the fund managers. This is done in three ways, first with two commonly used performance-risk measures, then with two-factor models and lastly with a panel data regression.

Table 4 - Summary statistics for group sizes

\begin{tabular}{lrrrrrc}
\hline \multicolumn{1}{c}{ Group } & \multicolumn{1}{c}{ Min } & \multicolumn{1}{c}{ Max } & Mean & Variation & Mean Return & Std deviation \\
\hline Small & 1251182 & 902833567 & 207929747 & $84 \%$ & 0.70 & $5.61 \%$ \\
Medium & 256519329 & 3684691000 & 880964019 & $49 \%$ & $0.79 \%$ & $5.74 \%$ \\
Large & 606643202 & 27531329010 & 4904563335 & $83 \%$ & $0.68 \%$ & $5.62 \%$ \\
\hline
\end{tabular}

Note: The table shows descriptive statistics in NOK for the funds in the sample.

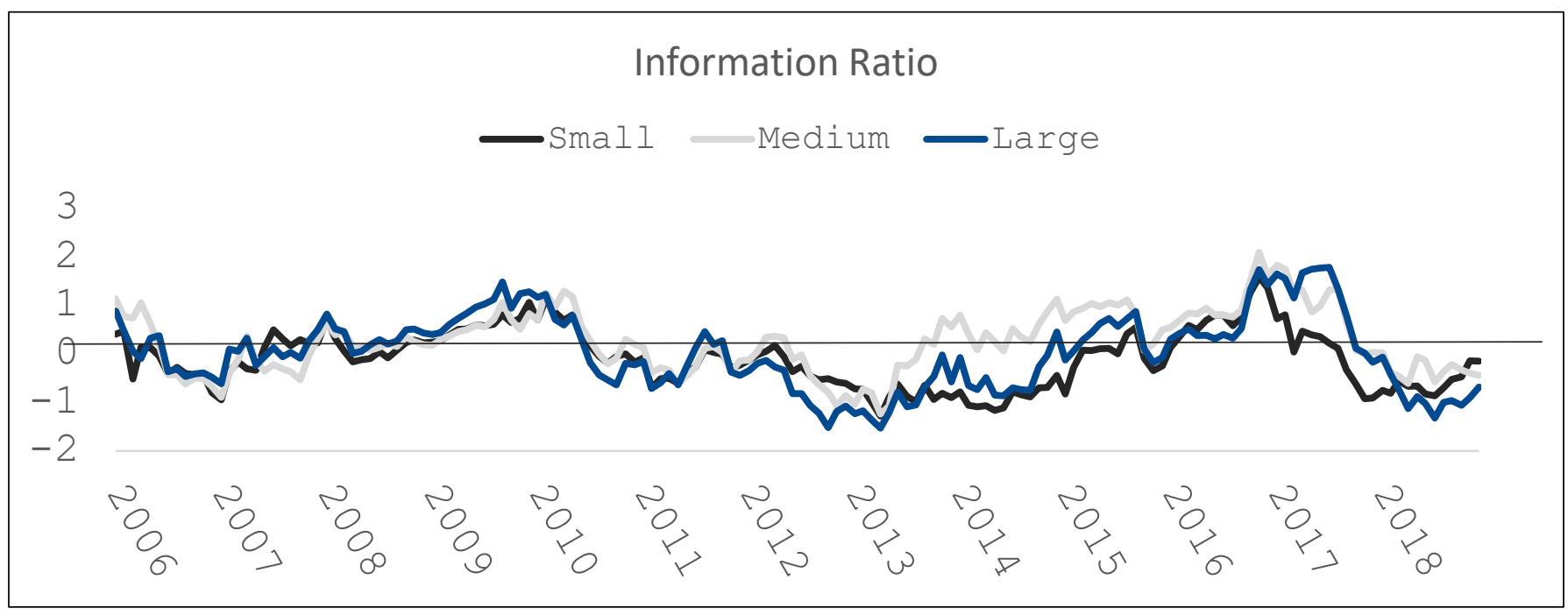

Figure 2- Information Ratio

\section{Information Ratio}

The Information Ratio (IR) or appraisal ratio, introduced by Jack Treynor and Fischer Black in 1973 (Treynor \& Black, 1973), measures the return in excess of a relevant benchmark index. For the purpose of this study, the IR is calculated with twelve months rolling window and presented in Figure 3. It seems as if Large funds outperformed the other groups in the years following the financial crisis in 2008 up until 2010. Even bigger differences can be seen in the period between 2013 and 2017 where funds in the Medium group did far better than the other groups, with Large being better than Small. By looking at the mean values in Table 5 the pattern from the later years seems to be making the biggest difference as Medium sized funds had an average annualized rolling IR of 0.259 in the whole period while Small and Large had -0.099 and 0.029 respectively. Moreover, studying the histogram and Q-Q Plots in Figure 1 a normal distribution is indicated, which is confirmed when doing a Shapiro-Wilk test for normality(Shapiro \& Wilk, 1965). This allows for t-tests to quantify the differences between the groups. Two-Sample t-tests are done between pairs of groups assuming equal variances of IR and 
t-statistics shows that the Medium group has done significantly better than both Small and Large groups. There is no significant difference between Small and Large.

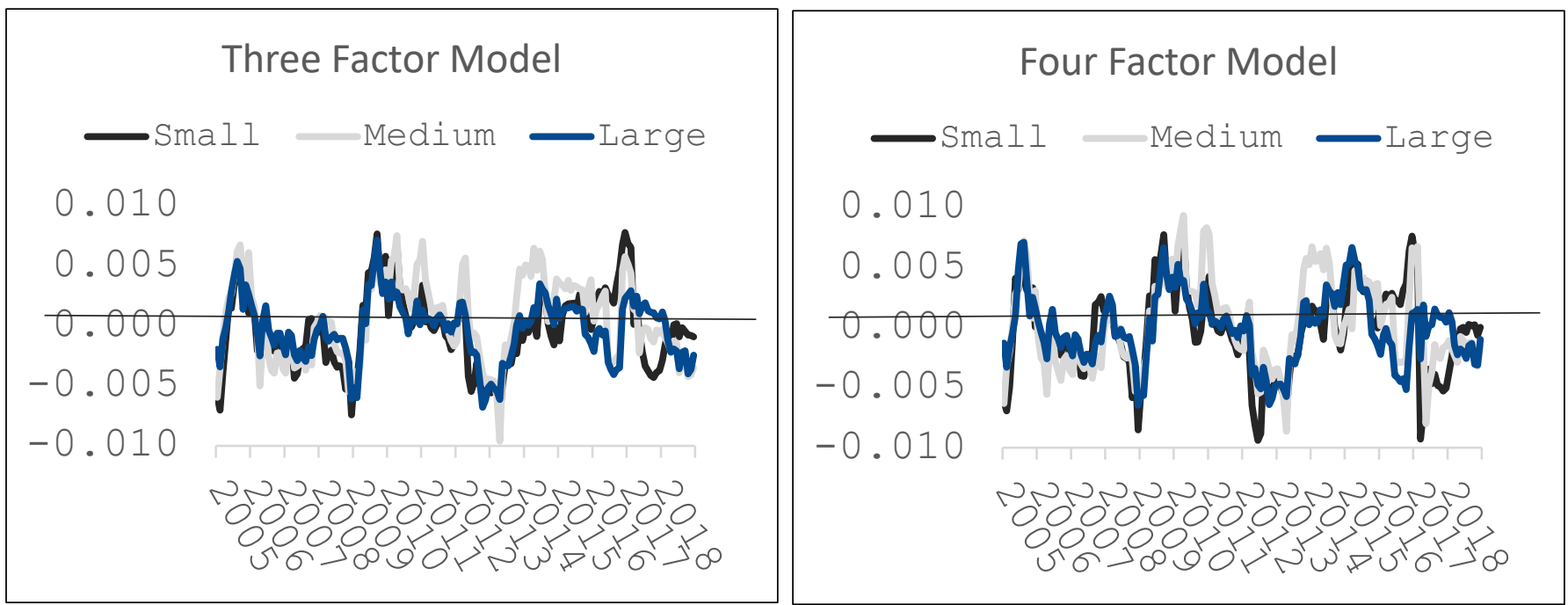

Figure 3 - Factor Models

Table 5 - Information Ratio

\begin{tabular}{lrrrr}
\hline & \multicolumn{2}{c}{ t-statistics } \\
\hline Group & Mean IR & Std.dev & Diff from Small & Diff from Medium \\
Small & -0.099 & 0.59 & & \\
Medium & 0.259 & 0.644 & 5.129 & 2.869 \\
Large & 0.029 & 0.644 & 1.645 & \\
\hline
\end{tabular}

Note: The table shows mean values, standard deviation and t-statistics from two-sample t-tests assuming equal variance for Information Ratio calculated as a twelve-month rolling average from 2005 to 2018.

\section{Factor Models}

The Fama-French Three Factor Model and the extended Carhart Four Factor Model use market risk, size, book-to-market and momentum factors in order to explain a fund's performance. These models are estimated for all funds in the data and the fund loadings between groups can be seen in Table 2. Using the extended model, I find that Medium sized funds have a higher mean alpha than both Small and Large. It is worth mentioning that only 5 out of 49 of the alphas in the sample had a low enough p-value to discard $\mathrm{H}_{0}$ of alpha $=0$ at a 5 percent significance level wherein adjusted $\mathrm{R}^{2}$ provides a goodness-of-fit measure of the model. The model explains most of the variation in performance of the bigger funds (0.953) and less for the smaller funds (0.835). As variations over time are of interest, the Factor Models are calculated with rolling twelve months averages for every fund. Group averages are then calculated allowing for funds to change group belongings through time. From the histograms and plots in Figure 1there seem to be a negative skewness in the Three Factor Model, while the Four Factor Model seems to be closer to a normal distribution. A Shapiro-Wilk test for normality (Shapiro \& Wilk, 1965) gives a p-value of 0.2567 and 0.2478 for the Three and Four Factor Model respectively. These are both above the critical value of 0.05 , indicating a normal distribution. Further, the plotted alpha values can be seen in Figure 4. Medium sized funds seem to outperform the other groups between 20092012 and 2013-2016 in both models. The table in Panel B shows that on average Medium sized funds outperform Small and Large funds in both models. Since the data is normally distributed, t-tests can be carried out to test if the differences are significant. In the Three Factor Model, Medium are significantly different from 
both Small and Large. This result is not consistent in the Four Factor Model where t-values are too low. In neither of the models are the Small funds significantly different from the Large funds.
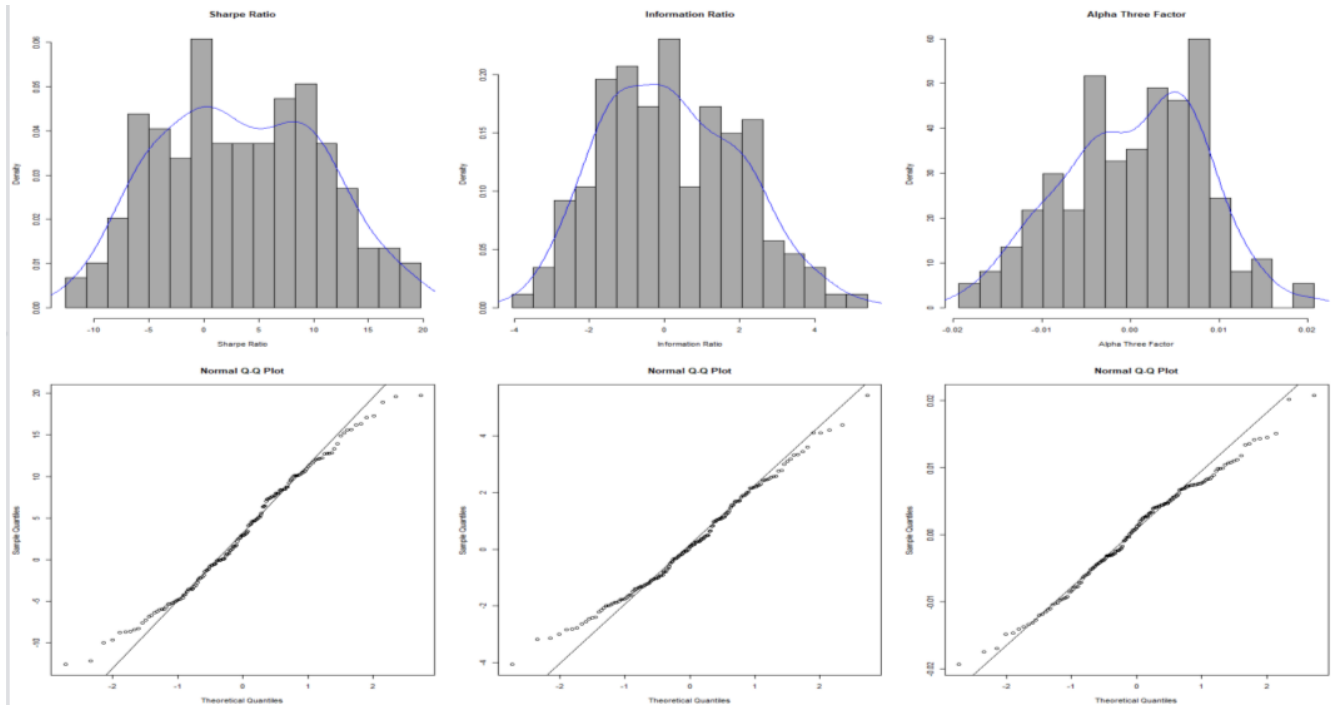

Figure 4 - Histograms and Q-Q-Plots
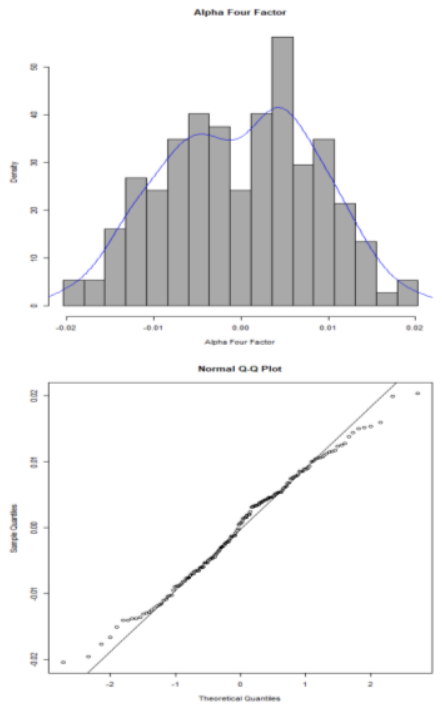

Table 6 - Factor Models

\begin{tabular}{|c|c|c|c|c|}
\hline \multicolumn{3}{|c|}{ Panel A: Three Factor Model } & \multicolumn{2}{|c|}{ t-statistics } \\
\hline Group & Mean $\alpha$ & Std dev & Diff from Small & Diff from Medium \\
\hline Small & -0.0003 & 0.0031 & & \\
\hline Medium & 0.0008 & 0.0032 & 2.93 & \\
\hline Large & -0.0001 & 0.0023 & 0.62 & 2.72 \\
\hline \multicolumn{5}{|c|}{ Panel B: Four Factor Model } \\
\hline Small & -0.0003 & 0.0035 & & \\
\hline Medium & 0.0004 & 0.0035 & 1.565 & \\
\hline Large & -0.0002 & 0.0025 & 0.307 & 1.508 \\
\hline
\end{tabular}

Note: The table shows mean values, standard deviation and t-statistics from two-sample t-tests assuming equal variance calculated with twelve months rolling windows from 2004 to 2018.

\section{Results and Discussion}

I find mixed evidence of performance erosion due to growth in the fund's asset base. I present the estimation results for the panel data regressions in Table 7. The coefficients for fund size are negative for all six models implying that on average, increase in size negatively affects the performance. This finding provides an answer to my first question and is in line with the findings of J. Chen et al. (2004) for US funds. For my pooled OLS models 1, 2 and 3, model 3 is statistically significant (at 0.01) and model 1 and 2 are marginally significant (at 0.1). The statistically significant coefficients are economically small wherein a $10 \%$ increase in AUM will reduce expected monthly risk-adjusted return by 5 bps annually for all three models controlled for the other variables in the models. As the pooled OLS is expected to produce biased results and if skill and size are positively correlated, the economic significance of changes in fund size is understated. Better managers attract more money and are probably hired to manage bigger funds. The disadvantages associated with bigger funds might, therefore, be hidden by the better-skilled managers as skill is not observed in this study.

The fixed effects models produce expectedly stronger negative results due to the regression to-the-mean bias, and t-values (between -6.831 and -4.490) make all coefficients statistically significant (at 0.01) for model 4, 5 
and 6. With a ten percent increase in funds AUM, monthly performance is expected to decrease annually by 25 bps, 20 bps and 35 bps respectively, controlled for the other variables in the models, which is of some economic significance though still modest. As the two estimation techniques probably give biases in separate directions, the biasfree coefficients can be assumed to be somewhere in between. This is in line with the findings from US funds where size erodes performance (H.-1. Chen \& Pennacchi, 2009; Pástor et al., 2015; Yan \& Analysis, 2008), but in contrast to the results of Ferreira et al. (2012) who find that the negative relationship does not exist outside the US.

Table 7 - Estimation results for the panel data regressions

\begin{tabular}{|c|c|c|c|c|c|c|}
\hline \multirow[t]{3}{*}{ Variables } & \multicolumn{3}{|c|}{ Pooled OLS } & \multicolumn{3}{|c|}{ Fixed Effects } \\
\hline & EXCRET3F & EXCRET4F & EXCRETM & EXCRET3F & EXCRET4F & EXCRETM \\
\hline & 1 & 2 & 3 & 4 & 5 & 6 \\
\hline \multirow{2}{*}{ FDS } & $-0.001 *$ & $-0.001 *$ & $-0.001 * * *$ & $-0.005^{* * *}$ & $-0.004 * * *$ & $-0.007 * * *$ \\
\hline & -1.95 & -1.73 & -3.205 & -5.706 & -4.49 & -6.831 \\
\hline \multirow[t]{2}{*}{ AGE } & 0.00004 & -0.0003 & 0.00001 & $0.006 * *$ & $0.005^{*}$ & 0.004 \\
\hline & 0.053 & -0.4 & 0.006 & 2.033 & 1.768 & 1.325 \\
\hline \multirow[t]{2}{*}{ ER } & 0.049 & 0.074 & 0.01 & & & \\
\hline & 0.995 & 1.6 & 0.175 & & & \\
\hline \multirow[t]{2}{*}{ FAS } & 0.0002 & 0.0002 & 0.0003 & -0.0004 & -0.0004 & 0.0003 \\
\hline & 0.919 & 0.816 & 0.871 & -0.841 & -0.777 & 0.547 \\
\hline \multirow[t]{2}{*}{ INS } & $-0.003 * * *$ & $-0.003 * * *$ & -0.001 & -0.001 & $-0.002 *$ & 0.001 \\
\hline & -3.492 & -4.149 & -0.832 & -1.004 & -1.698 & 0.303 \\
\hline \multirow[t]{2}{*}{ HHI } & 0.013 & -0.013 & $0.046^{*}$ & 0.015 & -0.01 & 0.032 \\
\hline & 0.563 & -0.609 & 1.723 & 0.617 & -0.438 & 1.15 \\
\hline \multirow[t]{2}{*}{ MFI } & 0.001 & 0.001 & -0.001 & & & \\
\hline & 0.995 & 0.96 & -0.851 & & & \\
\hline \multirow[t]{2}{*}{ SCI } & 0.001 & 0.0001 & -0.001 & & & \\
\hline & 0.569 & 0.073 & -0.852 & & & \\
\hline \multirow[t]{2}{*}{ MH } & 0.001 & 0.001 & 0.001 & 0.001 & 0.001 & 0.002 \\
\hline & 0.929 & 0.99 & 0.87 & 0.823 & 0.911 & 0.971 \\
\hline \multirow[t]{2}{*}{ FLO } & $0.005^{* * *}$ & $0.005^{* * *}$ & $0.004^{* * *}$ & $0.005^{* * *}$ & $0.004 * * *$ & $0.004^{* *}$ \\
\hline & 4.144 & 4.003 & 3.12 & 3.702 & 3.641 & 2.523 \\
\hline \multirow[t]{2}{*}{ Constant } & $0.037 * * *$ & $0.043^{* * *}$ & 0.016 & & & \\
\hline & 3.693 & 4.534 & 1.391 & & & \\
\hline Observations & 6194 & 6194 & 6194 & 6194 & 6194 & 6194 \\
\hline $\mathbf{R}^{2}$ & 0.007 & 0.008 & 0.005 & 0.011 & 0.009 & 0.011 \\
\hline Adjusted $\mathbf{R}^{2}$ & 0.006 & 0.006 & 0.004 & 0.002 & 0.001 & 0.002 \\
\hline F Statistic & $4.447 * * *$ & $5.013^{* * *}$ & 3.181 *** & $9.832^{* * *}$ & $8.307 * * *$ & $9.732^{* * *}$ \\
\hline
\end{tabular}

Note: The table reports estimation results using two estimators, pooled OLS and Fixed Effects. EXCRET3F is returns in excess of estimated return through a three-factor model. EXCRET4 extends estimation with a momentum factor. EXCRETM is returns in excess of benchmark return. FDS is the logarithm of funds AUM. AGE is the logarithm of funds age. ER is the annual expense ratio. FAS is the logarithm of the AUM of the owning family. INS is the logarithm of the AUM of all funds listed for sale in Norway. HHI is the Herfindahl-Hirschmann index. MFI and SCI are dummy variables taking 1 if the reported benchmark is Mutual Fund TR or Small Cap Index TR. MH is a dummy taking the value 1 if a change is made in managers. FLO is a measure of monthly fund flow, ${ }^{*} \mathrm{p}<0.1 ;{ }^{* *} \mathrm{p}<0.05 ;{ }^{* * *} \mathrm{p}<0.01$. 
A plausible explanation for the low $\mathrm{R}^{2}$ could be that many factors are expected to affect a fund's performance but are not included in the models as they are hard to observe or irrelevant for the relationship studied in this paper. However, all F-statistic are significant (at 0.01) suggesting that the specified models provide a better fit than an intercept-only model, making it possible to conclude from the coefficients. The most consistently statistically significant variable is Flow (t-values range from 2.523 to 4.144) in all models (at 0.01 for 1 to 5 and at 0.05 for 6 ). All coefficients are positive, indicating that funds that have experienced a positive cash flow in month t-1 perform better than funds with outflows. This finding reveals that the return on new cash flow is better than the average return for investors which gives support to the "smart money hypothesis" of (H.-l. Chen \& Pennacchi, 2009; Gruber, 1996) who argue that investors can predict future performance. Another explanation for the positive relationship is that managers invest new liquid capital in their best ideas that also help alter exposure. The coefficients (range from 0.004 to 0.005 ) indicate that a $10 \%$ increase in fund inflows will result in a 4-5 bps increase in fund performance, holding all other variables constant. This might seem small but keep in mind that funds have experienced an average annual inflow of 22.8 percent in the sample period. Further, the fund flows might affect the relationship between size and performance. A bigger asset base erodes performance but at the same time the inflows provide managers the possibility to change exposure.

J. Chen et al. (2004) find evidence of liquidity issues as the negative relationship of size is strongest for funds investing in small-cap stocks. If the same were true in the Norwegian market, I would expect the Small Cap Index variable to produce negative coefficients. However, the results presented in Table 6 do not provide any evidence to support this since two out of three coefficients are positive and none being statistically significant. Answering the second research question, the fund benchmark does not seem to affect the relationship between size and performance.

Table 8 - Excluding Small funds

\begin{tabular}{|c|c|c|c|c|c|c|}
\hline \multirow[t]{3}{*}{ Variables } & \multicolumn{3}{|c|}{ Pooled OLS } & \multicolumn{3}{|c|}{ Fixed Effects } \\
\hline & EXCRET3F & EXCRET4F & EXCRETM & EXCRET3F & EXCRET4F & EXCRETM \\
\hline & 1 & 2 & 3 & 4 & 5 & 6 \\
\hline \multirow[t]{2}{*}{ FDS } & $-0.001 * *$ & $-0.001 * * *$ & $-0.004 * * *$ & $-0.004 * * *$ & $-0.003^{* * *}$ & $-0.010 * * *$ \\
\hline & -2.421 & -2.807 & -5.679 & -4.365 & -3.404 & -7.323 \\
\hline \multirow[t]{2}{*}{ AGE } & 0.001 & -0.0002 & 0.001 & 0.002 & 0.003 & -0.003 \\
\hline & 0.739 & -0.315 & 1.216 & 0.506 & 0.090 & -0.691 \\
\hline \multirow[t]{2}{*}{ ER } & -0.032 & -0.019 & -0.085 & & & \\
\hline & -0.649 & -0.422 & -1.223 & & & \\
\hline \multirow[t]{2}{*}{ FAS } & 0.001 & 0.001 & $0.001 * *$ & 0.002 & 0.002 & $0.006 * * *$ \\
\hline & 1.554 & 1.611 & 2.497 & 1.468 & 1. .213 & 2.824 \\
\hline \multirow[t]{2}{*}{ INS } & $-0.004 * * *$ & $-0.004 * * *$ & -0.0003 & $-0.004^{*}$ & $-0.004 * *$ & 0.002 \\
\hline & -4.640 & -5.605 & -0.217 & -1.706 & -2.103 & 0.551 \\
\hline \multirow{2}{*}{ HHI } & -0.010 & $-0.040 * *$ & $0.058^{*}$ & -0.003 & $-0.037 *$ & $0.060 *$ \\
\hline & 0.460 & -1.973 & 1.856 & -0.122 & -1.695 & 1.814 \\
\hline \multirow[t]{2}{*}{ MFI } & 0.001 & 0.001 & 0.0001 & & & \\
\hline & 0.966 & 1.071 & 0.120 & & & \\
\hline \multirow[t]{2}{*}{ SCI } & 0.001 & 0.001 & 0.002 & & & \\
\hline & 0.909 & 1.007 & 1.453 & & & \\
\hline \multirow[t]{2}{*}{ MH } & 0.0002 & 0.0001 & 0.001 & 0.00003 & 0.0001 & 0.001 \\
\hline & 0.109 & 0.103 & 0.524 & 0.019 & 0.069 & 0.365 \\
\hline \multirow[t]{2}{*}{ FLO } & $0.008^{* * *}$ & $0.006^{* * *}$ & $0.010 * * *$ & $0.007 * * *$ & $0.006^{* * *}$ & $0.009 * *$ \\
\hline & 3.686 & 3.110 & 3.315 & 3.429 & 2.949 & 2.938 \\
\hline Constant & $0.053 * * *$ & $0.062^{* * *}$ & 0.023 & & & \\
\hline
\end{tabular}




\begin{tabular}{lllllll}
\hline & 5.498 & 6.991 & 1.713 & & & \\
Observations & 4200 & 4200 & 4200 & 4200 & 4200 & 4200 \\
$\mathbf{R}^{2}$ & 0.013 & 0.016 & 0.013 & 0.015 & 0.015 & 0.018 \\
Adjusted $\mathbf{R}^{2}$ & 0.010 & 0.013 & 0.010 & 0.004 & 0.005 & 0.007 \\
F Statistic & $5.350^{* * *}$ & $\mathbf{6 . 7 4 1 * * *}$ & $5.421 * * *$ & $8.761 * * *$ & $9.265^{* * *}$ & $10.662^{* * *}$ \\
Note: $\boldsymbol{*}_{\mathbf{p}}<\mathbf{0 . 1} ; \boldsymbol{* *} \mathbf{p}<\mathbf{0 . 0 5} ; \boldsymbol{* * *} \mathbf{p}<\mathbf{0 . 0 1}$ & & & &
\end{tabular}

Note: The table reports estimation results using two estimators, pooled OLS and Fixed Effects. EXCRET3F is returns in excess of estimated return through a three-factor model. EXCRET4 extends estimation with a momentum factor. EXCRETM is returns in excess of benchmark return. FDS is the logarithm of funds AUM. AGE is the logarithm of funds age. ER is the annual expense ratio. FAS is the logarithm of the AUM of the owning family. INS is the logarithm of the AUM of all funds listed for sale in Norway. HHI is the Herfindahl-Hirschmann index. MFI and SCI are dummy variables taking 1 if the reported benchmark is Mutual Fund TR or Small Cap Index TR. MH is a dummy taking the value 1 if a change is made in managers. FLO is a measure of monthly fund flow, ${ }^{*} \mathrm{p}<0.1 ; *{ }^{*} \mathrm{p}<0.05 ; * *{ }_{\mathrm{p}}<0.01$

Another interesting variable is Industry Size which five out of six models give negative coefficients. However, there are large variations in t-statistic (ranging from -4.149 to 0.303). While Model 1 and 2 are statistically significant at 0.01 , Model 5 is significant only at 0.1 , and the remaining models are insignificant. Even though hard to conclude, there are some signs that increases in the size of the mutual fund industry erode fund performance, possibly indicating that growth leads to fiercer competition. The size of the industry might affect the relationship between fund size and performance, which partly supports findings of (Pástor et al., 2015).

Table 9 - Excluding Large Funds

\begin{tabular}{|c|c|c|c|c|c|c|}
\hline \multirow[t]{3}{*}{ Variables } & \multicolumn{3}{|c|}{ Pooled OLS } & \multicolumn{3}{|c|}{ Fixed Effects } \\
\hline & EXCRET3F & EXCRET4F & EXCRETM & EXCRET3F & EXCRET4F & EXCRETM \\
\hline & 1 & 2 & 3 & 4 & 5 & 6 \\
\hline \multirow[t]{2}{*}{ FDS } & $-0.001 * *$ & -0.001 & -0.001 & $-0.007 * * *$ & $-0.005^{* * *}$ & $-0.009 * * *$ \\
\hline & -2.102 & -1.584 & -1.387 & -5.431 & -4.218 & -5.948 \\
\hline \multirow[t]{2}{*}{ AGE } & 0.0001 & -0.0002 & -0.0002 & $0.009 * *$ & $0.007 *$ & $0.009 * *$ \\
\hline & -0.087 & -0.181 & -0.209 & -2.402 & -1.948 & -2.274 \\
\hline \multirow[t]{2}{*}{ ER } & $0.114^{*}$ & $0.138^{* *}$ & -0.005 & & & \\
\hline & -1.698 & -2.173 & -0.063 & & & \\
\hline \multirow[t]{2}{*}{ FAS } & 0.0001 & 0.0001 & 0.0001 & -0.001 & -0.0004 & 0.00001 \\
\hline & -0.323 & -0.305 & -0.344 & -0.926 & -0.837 & -0.017 \\
\hline \multirow{2}{*}{ INS } & -0.002 & $-0.002 * *$ & -0.001 & -0.001 & -0.002 & -0.001 \\
\hline & -1.522 & -2.008 & -0.5 & -0.59 & -0.917 & -0.487 \\
\hline \multirow[t]{2}{*}{ HHI } & 0.034 & -0.0003 & 0.032 & 0.044 & 0.008 & 0.028 \\
\hline & -1.043 & -0.011 & -0.925 & -1.25 & -0.237 & -0.748 \\
\hline \multirow[t]{2}{*}{ MFI } & -0.001 & -0.001 & -0.00002 & & & \\
\hline & -0.663 & -0.93 & -0.024 & & & \\
\hline \multirow[t]{2}{*}{ SCI } & -0.002 & $-0.003 * *$ & -0.001 & & & \\
\hline & -1.612 & -2.178 & -0.486 & & & \\
\hline \multirow[t]{2}{*}{ MH } & 0.003 & 0.003 & 0.002 & 0.003 & 0.003 & 0.003 \\
\hline & -1.423 & -1.43 & -0.973 & -1.345 & -1.322 & -1.045 \\
\hline \multirow[t]{2}{*}{ FLO } & $0.005^{* * *}$ & $0.004 * * *$ & $0.004 * *$ & $0.004^{* * *}$ & $0.004 * * *$ & $0.003^{*}$ \\
\hline & -3.067 & -2.999 & -2.434 & -2.67 & -2.669 & -1.818 \\
\hline Constant & $0.028^{* *}$ & $0.033 * *$ & 0.013 & & & \\
\hline
\end{tabular}




\begin{tabular}{lllllll}
\hline & -2.073 & -2.572 & -0.878 & & & \\
Observations & 4153 & 4153 & 4153 & 4153 & 4153 & 4153 \\
R2 & 0.007 & 0.007 & 0.003 & 0.012 & 0.009 & 0.011 \\
Adjusted R2 & 0.005 & 0.005 & 0.001 & -0.0003 & -0.004 & -0.001 \\
F Statistic & $2.956^{* * *}$ & $3.106^{* * *}$ & 1.305 & $7.082^{* * *}$ & $5.131^{* * *}$ & $6.773^{* * *}$ \\
Note: $\boldsymbol{*} \mathbf{p}<\mathbf{0 . 1} ; \boldsymbol{*} \mathbf{p}<\mathbf{0 . 0 5} ; * * * \mathbf{p}<\mathbf{0 . 0 1}$ & & & & \\
\hline
\end{tabular}

Note: The table reports estimation results using two estimators, pooled OLS and Fixed Effects. EXCRET3F is returns in excess of estimated return through a three-factor model. EXCRET4 extends estimation with a momentum factor. EXCRETM is returns in excess of benchmark return. FDS is the logarithm of funds AUM. AGE is the logarithm of funds age. ER is the annual expense ratio. FAS is the logarithm of the AUM of the owning family. INS is the logarithm of the AUM of all funds listed for sale in Norway. HHI is the Herfindahl-Hirschmann index. MFI and SCI are dummy variables taking 1 if the reported benchmark is Mutual Fund TR or Small Cap Index TR. MH is a dummy taking the value 1 if a change is made in managers. FLO is a measure of monthly fund flow, ${ }^{*} \mathrm{p}<0.1 ; *^{*} \mathrm{p}<0.05 ; * * * \mathrm{p}<0.01$

Performance metrics used to identify differences among group size indicated that medium-sized funds outperformed both small and large funds. This indicates a nonlinearity implying that a regression model for the aggregate data might not be suitable. Consequently, I carried out the panel data regressions on subsamples of the data. To be more specific, the same models are applied twice, first by excluding the smallest funds throughout the whole period, then by excluding the biggest funds. Table 8 presents the results for the first subsample, excluding the smallest funds. Fund Size is now statistically significant at 0.01 for all models except for Model 1, which is significant at the 0.05. Improved significance confirms my assertion that there is decreasing performance to scale for the bigger funds in my sample. Looking closer at the strength of the coefficients, I find that Model 3 and 6 which both has EXCRETM as the dependent variable show stronger economic significance while the other models are unchanged or show weaker effects. Notice also that all R2 values increase by about the double, implying that the models fit better for these funds than they do for the entire sample. If the relationship between size and performance is as concave as analyses of fund performance show, I could expect the coefficients for Fund Size to become positive when excluding the large funds. Table 9 shows that this is not entirely the case. Model 2 and 3 now produce insignificant coefficients. Model 4, 5 and 6 are still negative and statistically significant at 0.01 , while Model 1 is negative and statistically significant at 0.05. Moreover, goodness-of-fit measures decrease showing that the models explain less of the changes in the dependent variables than the models including the larger funds. It might still be true that there is a nonlinear relationship, but that the positive relationships among smaller funds are weaker and valid only for the very small funds, being outweighed by the negative relationships among the medium-sized funds. Dividing the funds into smaller groups might have given a clearer picture but it could not be done as that would have made the groups too small.

Plots of historical fund performance (Figure 3) indicate that the relationship between size and performance has changed through time. To account for this, the regression framework is applied to three different periods of 56 months each: from January 2005 to August 2009; from September 2009 to April 2014; and from May 2014 to December 2018. Regression results can be seen in Table 10-12, showing some patterns. Period 1 and 2 seem to produce similar results, with Fund Size coefficients being statistically significant only for models using fund fixed effects (4, 5 and 6). Model fit seems to be rather poor, especially for pooled OLS models where f-statistics are not significant at all in period 2. Specifications seem to be better in period 3 where all f-statistics are statistically significant at either 0.05 or 0.01 level. Fund Size is negative in all models, with t-statistics ranging from 2.519 to 5.786. Model 2 shows a coefficient statistically significant at the 0.05 level and the other models at the 0.01 level. The magnitude of the coefficients is still rather modest, but the relationship has been stronger in the later years, confirming what was found when studying group performance in terms of Information ratio and alpha values (Figure 3 and 4). Some interesting evidence on the role of competition can be found in period 
3. All models show negative coefficients for Industry Size, giving hints that a bigger industry makes it harder to produce positive alphas, controlled for other variables. Model 3 and 6 is statistically significant at the 0.01 level, model 1 at the 0.05 level, while the other three models do not find the coefficients significant. More competition in terms of a bigger market erodes performance. At the same time, HHI also shows negative coefficients. Model 3 and 6 shows significant coefficients at the 0.01 level, model 1 and 4 at the 0.05 level and model 2 and 5 show no statistical significance. As higher index values indicate a decrease in competition, a negative coefficient implies that a decrease in competition reduces fund performance. An explanation for this might be that the incentive to perform is lower with lower competition which erodes performance. Answering the second thesis question, the degree of competition might affect the relationship between size and performance in some periods by providing managers a need to perform.

In summation, I find some evidence that a bigger fund will imply poor performance, while a more competitive fund will imply better performance. These results are in line with findings from the US markets. Pástor et al. (2015) find a negative relationship between the size of the active mutual fund industry and fund performance and Feldman, Saxena, and $\mathrm{Xu}$ (2020) find evidence that a decrease in the mutual fund industry concentration gives a decrease in net alpha.

Table 10 - Period 1

\begin{tabular}{|c|c|c|c|c|c|c|}
\hline \multirow[t]{3}{*}{ Variables } & \multicolumn{3}{|c|}{ Pooled OLS } & \multicolumn{3}{|c|}{ Fixed Effects } \\
\hline & EXCRET3F & EXCRET4F & EXCRETM & EXCRET3F & EXCRET4F & EXCRETM \\
\hline & 1 & 2 & 3 & 4 & 5 & 6 \\
\hline \multirow[t]{2}{*}{ FDS } & -0.001 & -0.001 & -0.001 & $-0.014^{* * *}$ & $-0.010 * * *$ & $-0.011 * * *$ \\
\hline & -0.771 & -0.707 & -0.783 & -4.298 & -3.362 & -3.567 \\
\hline \multirow[t]{2}{*}{ AGE } & -0.0002 & -0.001 & $-0.004^{*}$ & $0.042^{* * *}$ & $0.025^{* *}$ & 0.02 \\
\hline & -0.092 & -0.527 & -1.852 & -3.251 & -2.02 & -1.556 \\
\hline \multirow[t]{2}{*}{ ER } & 0.237 & $0.261 *$ & -0.122 & & & \\
\hline & -1.645 & -1.884 & -0.88 & & & \\
\hline \multirow[t]{2}{*}{ FAS } & 0.001 & 0.001 & 0.001 & $0.008^{*}$ & 0.007 & 0.003 \\
\hline & -0.741 & -0.843 & -0.597 & -1.698 & -1.559 & -0.667 \\
\hline \multirow[t]{2}{*}{ INS } & 0.005 & 0.004 & -0.009 & -0.004 & -0.004 & -0.006 \\
\hline & -0.816 & -0.748 & -1.564 & -0.567 & -0.539 & -0.88 \\
\hline \multirow[t]{2}{*}{ HHI } & -0.019 & -0.024 & $-0.315^{* * *}$ & $0.242^{* *}$ & 0.139 & -0.134 \\
\hline & -0.264 & -0.347 & -4.536 & -2.321 & -1.383 & -1.327 \\
\hline \multirow[t]{2}{*}{ MFI } & 0.0003 & 0.0005 & 0.002 & & & \\
\hline & -0.21 & -0.341 & -1.16 & & & \\
\hline \multirow[t]{2}{*}{ SCI } & 0.001 & 0.002 & 0.0002 & & & \\
\hline & -0.518 & -0.708 & -0.088 & & & \\
\hline \multirow[t]{2}{*}{ MH } & 0.002 & 0.002 & 0.003 & 0.002 & 0.001 & 0.004 \\
\hline & -0.637 & -0.521 & -0.969 & -0.453 & -0.256 & -1.02 \\
\hline \multirow[t]{2}{*}{ FLO } & $0.007 * * *$ & $0.007 * * *$ & 0.002 & $0.005^{* *}$ & $0.006^{* * *}$ & 0.001 \\
\hline & -3.151 & -3.206 & -1.139 & -2.524 & -2.666 & -0.564 \\
\hline \multirow[t]{2}{*}{ Constant } & -0.052 & -0.047 & $0.135^{* *}$ & & & \\
\hline & -0.787 & -0.729 & -2.118 & & & \\
\hline Observations & 1793 & 1793 & 1793 & 1793 & 1793 & 1793 \\
\hline $\mathbf{R} 2$ & 0.009 & 0.01 & 0.018 & 0.017 & 0.013 & 0.018 \\
\hline
\end{tabular}




\begin{tabular}{lcccccc}
\hline Adjusted R2 & 0.004 & 0.004 & 0.013 & -0.007 & -0.012 & -0.007 \\
F Statistic & $1.631^{*}$ & $1.808^{*}$ & $3.326^{* * *}$ & $4.432^{* * *}$ & $3.193^{* * *}$ & $4.476^{* * *}$ \\
\hline
\end{tabular}

Note: The table reports estimation results using two estimators, pooled OLS and Fixed Effects. EXCRET3F is returns in excess of estimated return through a three-factor model. EXCRET4 extends estimation with a momentum factor. EXCRETM is returns in excess of benchmark return. FDS is the logarithm of funds AUM. AGE is the logarithm of funds age. ER is the annual expense ratio. FAS is the logarithm of the AUM of the owning family. INS is the logarithm of the AUM of all funds listed for sale in Norway. HHI is the Herfindahl-Hirschmann index. MFI and SCI are dummy variables taking 1 if the reported benchmark is Mutual Fund TR or Small Cap Index TR. MH is a dummy taking the value 1 if a change is made in managers. FLO is a measure of monthly fund flow, ${ }^{*} \mathrm{p}<0.1 ;{ }^{* *} \mathrm{p}<0.05 ;{ }^{* * *} \mathrm{p}<0.01$

Table 11 - Period 2

\begin{tabular}{|c|c|c|c|c|c|c|}
\hline \multirow[t]{3}{*}{ Variables } & \multicolumn{3}{|c|}{ Pooled OLS } & \multicolumn{3}{|c|}{ Fixed Effects } \\
\hline & EXCRET3F & EXCRET4F & EXCRETM & EXCRET3F & EXCRET4F & EXCRETM \\
\hline & 1 & 2 & 3 & 4 & 5 & 6 \\
\hline \multirow[t]{2}{*}{ FDS } & -0.0004 & -0.0004 & -0.0004 & $-0.007 * * *$ & $-0.006 * * *$ & $-0.005^{*}$ \\
\hline & -0.931 & -0.904 & -0.774 & -3.535 & -3.15 & -1.921 \\
\hline \multirow[t]{2}{*}{ AGE } & 0.001 & 0.0004 & $0.002 *$ & 0.007 & 0.01 & 0.012 \\
\hline & -0.797 & -0.419 & -1.774 & -0.989 & -1.539 & -1.386 \\
\hline \multirow[t]{2}{*}{ ER } & -0.051 & -0.017 & -0.013 & & & \\
\hline & -0.885 & -0.321 & -0.176 & & & \\
\hline \multirow[t]{2}{*}{ FAS } & -0.0002 & -0.0001 & -0.0003 & -0.001 & -0.001 & -0.0003 \\
\hline & -0.725 & -0.243 & -0.816 & -1.29 & -1.435 & -0.511 \\
\hline \multirow[t]{2}{*}{ INS } & 0.004 & $0.005^{* *}$ & -0.003 & 0.005 & 0.004 & -0.007 \\
\hline & -1.55 & -1.993 & -0.954 & -1.128 & -1.029 & -1.336 \\
\hline \multirow[t]{2}{*}{ HHI } & 0.003 & -0.072 & 0.1 & 0.018 & -0.052 & 0.109 \\
\hline & -0.057 & -1.504 & -1.487 & -0.341 & -1.074 & -1.619 \\
\hline \multirow{2}{*}{ MFI } & -0.001 & 0.0001 & -0.001 & & & \\
\hline & -0.669 & -0.214 & -1.49 & & & \\
\hline \multirow[t]{2}{*}{ SCI } & 0.00001 & 0.0004 & -0.001 & & & \\
\hline & -0.01 & -0.377 & -0.565 & & & \\
\hline \multirow[t]{2}{*}{ MH } & -0.002 & -0.002 & 0.0002 & -0.002 & -0.002 & 0.001 \\
\hline & -1.028 & -1.063 & -0.098 & -0.979 & -1.019 & -0.352 \\
\hline \multirow[t]{2}{*}{ FLO } & 0.003 & 0.002 & 0.005 & 0.002 & 0.001 & 0.003 \\
\hline & -1.112 & -0.716 & -1.483 & -0.813 & -0.571 & -0.985 \\
\hline \multirow[t]{2}{*}{ Constant } & -0.039 & -0.043 & 0.033 & & & \\
\hline & -1.317 & -1.604 & -0.884 & & & \\
\hline Observations & 2252 & 2252 & 2252 & 2252 & 2252 & 2252 \\
\hline $\mathbf{R} 2$ & 0.004 & 0.004 & 0.005 & 0.01 & 0.01 & 0.005 \\
\hline Adjusted R2 & -0.001 & -0.001 & 0.001 & -0.013 & -0.013 & -0.018 \\
\hline F Statistic & 0.788 & 0.857 & 1.19 & $3.042^{* * *}$ & $3.161 * * *$ & 1.541 \\
\hline
\end{tabular}

Note: The table reports estimation results using two estimators, pooled OLS and Fixed Effects. EXCRET3F is returns in excess of estimated return through a three-factor model. EXCRET4 extends estimation with a momentum factor. EXCRETM is returns in excess of benchmark return. FDS is the logarithm of funds AUM. AGE is the logarithm of funds age. ER is the annual expense ratio. FAS is the logarithm of the AUM of the owning family. INS is the logarithm of the AUM of all funds listed for sale in Norway. HHI is the Herfindahl-Hirschmann index. MFI and SCI are dummy variables taking 1 if the reported benchmark is Mutual Fund TR or 
Small Cap Index TR. MH is a dummy taking the value 1 if a change is made in managers. FLO is a measure of monthly fund flow, ${ }^{*} \mathrm{p}<0.1 ;{ }^{*} \mathrm{p}<0.05 ;{ }^{* * *} \mathrm{p}<0.01$

Table 12 - Period 3

\begin{tabular}{|c|c|c|c|c|c|c|}
\hline \multirow[t]{3}{*}{ Variables } & \multicolumn{3}{|c|}{ Pooled OLS } & \multicolumn{3}{|c|}{ Fixed Effects } \\
\hline & EXCRET3F & EXCRET4F & EXCRETM & EXCRET3F & EXCRET4F & EXCRETM \\
\hline & 1 & 2 & 3 & 4 & 5 & 6 \\
\hline \multirow[t]{2}{*}{ FDS } & $-0.001 * * *$ & $-0.001 * *$ & $-0.002^{* * *}$ & $-0.008 * * *$ & $-0.005^{* * *}$ & $-0.014 * * *$ \\
\hline & -2.669 & -2.519 & -3.013 & -4.412 & -2.975 & -5.786 \\
\hline \multirow[t]{2}{*}{ AGE } & -0.0001 & 0.00005 & 0.0001 & $0.011 * *$ & $0.013 * *$ & $0.021 * * *$ \\
\hline & -0.149 & -0.052 & -0.052 & -1.98 & -2.474 & -2.822 \\
\hline \multirow[t]{2}{*}{ ER } & 0.042 & 0.071 & 0.059 & & & \\
\hline & -0.65 & -1.206 & -0.67 & & & \\
\hline \multirow[t]{2}{*}{ FAS } & 0.001 & 0.0002 & $0.001 *$ & 0.004 & 0.002 & 0.002 \\
\hline & -1.458 & -0.463 & -1.843 & -0.89 & -0.568 & -0.322 \\
\hline \multirow[t]{2}{*}{ INS } & $-0.011^{* *}$ & -0.002 & $-0.050 * * *$ & -0.01 & -0.007 & $-0.045^{* * *}$ \\
\hline & -2.067 & -0.51 & -6.95 & -1.26 & -0.897 & -4.179 \\
\hline \multirow[t]{2}{*}{ HHI } & $-0.176^{* *}$ & -0.105 & $-0.533 * * *$ & $-0.157 * *$ & -0.089 & $-0.468^{* * *}$ \\
\hline & -2.498 & -1.626 & -5.522 & -2.179 & -1.334 & -4.814 \\
\hline \multirow[t]{2}{*}{ MFI } & -0.001 & -0.001 & -0.001 & & & \\
\hline & -1.012 & -0.742 & -0.775 & & & \\
\hline \multirow[t]{2}{*}{ SCI } & -0.002 & -0.001 & -0.001 & & & \\
\hline & -1.118 & -0.521 & -0.722 & & & \\
\hline \multirow[t]{2}{*}{ MH } & $0.005^{* *}$ & $0.005^{* * *}$ & 0.001 & $0.005^{* *}$ & $0.006^{* * *}$ & 0.003 \\
\hline & -2.272 & -2.776 & -0.303 & -2.434 & -2.983 & -0.85 \\
\hline \multirow[t]{2}{*}{ FLO } & 0.001 & -0.0001 & 0.005 & -0.001 & -0.001 & 0.001 \\
\hline & -0.32 & -0.035 & -1.526 & -0.378 & -0.513 & -0.449 \\
\hline \multirow[t]{2}{*}{ Constant } & $0.153^{* *}$ & 0.047 & $0.660 * * *$ & & & \\
\hline & -2.281 & -0.769 & -7.178 & & & \\
\hline Observations & 2149 & 2149 & 2149 & 2149 & 2149 & 2149 \\
\hline $\mathbf{R} 2$ & 0.011 & 0.009 & 0.032 & 0.016 & 0.01 & 0.045 \\
\hline Adjusted R2 & 0.006 & 0.005 & 0.028 & -0.008 & -0.013 & 0.022 \\
\hline F Statistic & $2.290 * *$ & $2.028 * *$ & $7.109 * * *$ & $4.824 * * *$ & $3.094 * * *$ & $14.112^{* * *}$ \\
\hline \multicolumn{7}{|c|}{ Note: $*_{\mathrm{p}}<0.1 ; * * \mathrm{p}<0.05 ; * * * \mathrm{p}<0.01$} \\
\hline
\end{tabular}

Note: The table reports estimation results using two estimators, pooled OLS and Fixed Effects. EXCRET3F is returns in excess of estimated return through a three-factor model. EXCRET4 extends estimation with a momentum factor. EXCRETM is returns in excess of benchmark return. FDS is the logarithm of funds AUM. AGE is the logarithm of funds age. ER is the annual expense ratio. FAS is the logarithm of the AUM of the owning family. INS is the logarithm of the AUM of all funds listed for sale in Norway. HHI is the Herfindahl-Hirschmann index. MFI and SCI are dummy variables taking 1 if the reported benchmark is Mutual Fund TR or Small Cap Index TR. MH is a dummy taking the value 1 if a change is made in managers. FLO is a measure of monthly fund flow, ${ }^{*} \mathrm{p}<0.1 ; * * \mathrm{p}<0.05 ;{ }^{* * *} \mathrm{p}<0.01$

\section{Robustness and Diagnostics}

A series of diagnostic tests are run to test the robustness of the analysis. The Variation Inflation Factor is calculated to test how much of the variance of the estimated regression coefficients is inflated due to covariance with other variables. Results can be seen in Table 4. All values lie in the interval 1 - 1.6, implying moderate 
collinearity which should not impose a significant problem for the estimates in the panel data models. A Breusch-Pagan test is conducted, showing no signs of heteroskedasticity. Control variables are included in the model to account for the possibility that they might correlate with fund size as well as affecting fund performance. Lastly, the models are applied on different subsamples of the data and on different time periods. This produce differences in the estimators, indicating that the results are not perfectly consistent through time.

\section{Conclusions and Policy Implications}

Using panel data technique, this paper empirically analyzes the relationship between performance and size of Norwegian mutual funds and contributes with an increased understanding of several drivers of the performance. I find mixed evidence, mainly indicating that there is a negative relationship between lagged fund size and performance. The negative relationship seems to be nonlinear as bigger funds suffer more from increases than medium and smaller sized funds. Some evidence also points towards a positive relationship for the smallest funds, indicating that funds might be too small to justify an active strategy. This compliment earlier studies in the US as it finds that relationships found in the US are also valid for smaller Norwegian market with lesser participants. However, I suggest further studies to see if it is universal or if Norway is a special case of small markets.

I use several adjustments for risk to answer the first question "Does the size of a fund's asset base affect risk adjusted performance among Norwegian mutual funds investing in Norwegian equities? Firstly, dividing funds into three groups for size reveals significant differences when analyzing information ratio and estimated alpha from multi-factor models. Both small and large funds underperform against the medium-sized funds, implying that size does affect the performance. This finding is not consistent as no significant differences are found using the Sharpe ratio.

Secondly, a panel data model is proposed to control for other variables assumingly affecting the risk-adjusted performance. Two estimators are considered, each expected to produce biases in opposite directions. Presenting both gives a more nuanced answer to the second research question. Six regression models provide mixed evidence that growth in the size of a fund's asset base erodes performance. All models produce negative coefficients although of varying significance. Overall, economic significance seems to be small but present.

The suspicion of nonlinearity is strengthened after applying the regression models to subsamples of the data. Regressions done after excluding the smallest funds show more significant coefficients, implying that the negative relationship is more robust for relatively bigger funds. Applying the models on three different periods, show that the relationship between size and performance has changed through time, with the last five years showing better fit to the data and higher significance of coefficients. Including control variables also provide answers to the second research question: "Are there any factors affecting the relationship between size and performance?" A positive correlation between fund inflow and performance is found for all panel data models. This relationship indicates that return on new cash flow is better than the average return, either showing that investors to some extent predict future performance or that liquid funds are valuable for the managers as they can make alterations in exposure.

Further, I find mixed evidence in the whole sample of a negative correlation between the size of the mutual fund industry and fund performance. More money competing for good deals give a more efficient market, making it harder for managers to outperform their passive benchmarks. I also find significant negative relations between competition density (HHI) and fund performance in the latest period, indicating that a more competitive industry improves performance. No evidence of liquidity issues is found as no coefficients concerning fund strategy (small-cap funds) are statistically significant. Furthermore, I do not find evidence of reasons for the negative relationship between size and performance, but existing literature shows that liquidity 
and price movement play important roles in the US market (J. Chen et al., 2004). The smallest funds seem to be too small to justify the cost of an active strategy, while the biggest funds overinvest in information and suffer higher transaction costs (Indro et al., 1999). As bigger blocks of trades must be done, managers move prices and take longer time to complete changes in exposure, which negatively hurts performance. Further studies will have to be done to investigate if the same reasons apply to the Norwegian market.

With the money management industry constantly evolving, companies take new approaches to attract customers. One of the biggest participants in the Norwegian market, DNB, recently changed their fee structure by reducing the fixed fee and introducing a performance fee (DNB, 2019). The fund's performance now plays a bigger role for their profits than before, and size becomes more of an issue. Previously, a bigger fund would have produced higher income, but now this is only true if the magnitude of size outweighs the loss of performance. If performance-based rewards are a trend being followed by other companies, findings in this paper implicate that we might start to see managers putting limits to the size of their funds. If performance became the direct source for income, managers would have to carefully consider factors affecting that performance, fund size being one of them. Companies might open several funds and hire more people in the search for new investments, which proves to mediate the relationship between size and performance (J. Chen et al., 2004). Also, having strategies such as keeping cash reserves and investing in more liquid assets to cope with liquidity issues might become a bigger focus for managers. Funds introducing performance-based fee structures align the interest of the managers and investors, although the risk structure is still asymmetric. A stronger incentive to produce positive alphas might make for better performance, but it might also make for alterations in risk. Especially if the basis for the success fee is reset every year, an underperforming fund might take undesirable risk at the end of the year in a last attempt to end up on the positive side, with the downside being mostly on the investor side. Regulators should make sure success fees are applied with a watermark solution where the principal investment sets the basis for the success fee and further reduce agency costs. Allowing for more funds to enter the market might also be good for the investor as a lower density of competition is good for performance.

Understanding the effects of scale on fund performance is of importance to investors both to pick the best funds and knowing when to invest or withdraw. By being aware of how economies of scale may affect their agency relationship to managers, investors can choose compensation contracts (fee structures) that will best serve them. Independent intermediaries should analyze how funds are exposed to liquidity risk and problems concerning scale to provide investors with the knowledge needed to make informative decisions. I control for various variables that might co-vary with fund size and performance, but potentially important factors are excluded due to lack of data or observability. These factors could affect the relationship and should be explored further. It might be that performance benchmarks are inadequate proxies for fund strategy or that cash holdings could make up for some of the disadvantages that extreme variations of size may bring. Nevertheless, investors should pay close attention to the size of the fund's asset base and how fund managers are planning to cope with price and liquidity issues.

Funding: This paper received scholarship support from Oslo Business School, Faculty of Social Sciences, Oslo Metropolitan University Norway.

Acknowledgments: Markus would like to thank Muhammad Azeem Qureshi, John Harald Henriksen, Niklas Hallberg, Alexander Miller, Sindre Støer, Per Kristian Gilleshammer, Einar Belsom and Ole Kristian Busterud for helpful comments.

Conflicts of Interest: The author declare no conflict of interest. The funders had no role in the design of the study; in the collection, analyses, or interpretation of data; in the writing of the manuscript, or in the decision to publish the results. 


\section{References}

Bank, N. (2019, February 1). Norges-Bank.no. Retrieved from https://www.norgesbank.no/en/Statistics/Historical-monetary-statistics/Short-term-interest-rates/

Børs, O. (2018, February 1). Statistikk. Retrieved from https://www.oslobors.no/Oslo-Boers/Statistikk

Carhart, M. M. (1997). On Persistence in Mutual Fund Performance. The Journal of Finance, 52(1), 57-82. doi:10.1111/j.1540-6261.1997.tb03808.x

Chen, H.-1., \& Pennacchi, G. G. (2009). Does prior performance affect a mutual fund's choice of risk? Theory and further empirical evidence. Journal of Financial Quantitative Analysis, 44(4), 745-775.

Chen, J., Hong, H., Huang, M., \& Kubik, J. D. (2004). Does Fund Size Erode Mutual Fund Performance? The Role of Liquidity and Organization. The American Economic Review, 94(5), 1276-1302.

DNB. (2019, March 09). Vi har satt ned prisene på de fleste av våre fond. Retrieved from https://www.dnb.no/privat/sparing-og-investering/fond/ny-prismodell.html

EuropeanParliament. (2014). Council of the European Union. (2014). Directive COD 2012/0168, EEA relevance, Com 2012/0350.

https:/ / oeil.secure.europarl.europa.eu/ oeil/popups/ ficheprocedure.do?reference $=2012 / 0168 \% 28 C O D \% 29 \& /=e n$.

Fama, E. F., \& French, K. R. (1993). Common risk factors in the returns on stocks and bonds. Journal of Financial Economics, 33(1), 3-56. doi:https://doi.org/10.1016/0304-405X(93)90023-5

Fama, E. F., \& French, K. R. (2010). Luck versus Skill in the Cross-Section of Mutual Fund Returns. The Journal of Finance, 65(5), 1915-1947. doi:10.1111/j.1540-6261.2010.01598.x

Fama, E. F., \& French, K. R. (2015). A five-factor asset pricing model. Journal of Financial Economics, 116(1), 1 22. doi:https://doi.org/10.1016/i.jifineco.2014.10.010

Fama, E. F., \& French, K. R. (2017). International tests of a five-factor asset pricing model. Journal of Financial Economics, 123(3), 441-463. doi:https://doi.org/10.1016/j.jfineco.2016.11.004

Feldman, D., Saxena, K., \& Xu, J. (2020). Is the active fund management industry concentrated enough? Journal of Financial Economics, 136(1), 23-43. doi:https://doi.org/10.1016/i.jfineco.2019.08.009

Ferreira, M. A., Keswani, A., Miguel, A. F., Ramos, S. B. J. J. o. B., \& Finance. (2012). The flow-performance relationship around the world. 36(6), 1759-1780.

Gruber, M. J. (1996). Another Puzzle: The Growth in Actively Managed Mutual Funds. The Journal of Finance, 51(3), 783-810.

Indro, D. C., Jiang, C. X., Hu, M. Y., \& Lee, W. Y. (1999). Mutual Fund Performance: Does Fund Size Matter? Financial Analysts Journal, 55(3), 74-87. doi:10.2469/faj.v55.n3.2274

Jensen, M. C. (1968). The Performance of Mutual Funds in the period 1945-1964. The Journal of Finance, 23(2), 389-419.

Pástor, L., Stambaugh, R. F., \& Taylor, L. A. (2015). Scale and skill in active management. Journal of Financial Economics, 116(1), 23-45. doi:https://doi.org/10.1016/j.jfineco.2014.11.008

Perold, A. F., \& Robert S. Salomon, Jr. (1991). The Right Amount of Assets under Management. Financial Analysts Journal, 47(3), 31-39.

Ross, S. A. (1976). The arbitrage theory of capital asset pricing. Journal of Economic Theory, 13(3), 341-360. doi:https://doi.org/10.1016/0022-0531(76)90046-6

Shapiro, S. S., \& Wilk, M. B. (1965). An analysis of variance test for normality (complete samples). Biometrika Vol. 52, No.3/4, 591-611.

Sharpe, W. F. (1964). CAPITAL ASSET PRICES: A THEORY OF MARKET EQUILIBRIUM UNDER CONDITIONS OF RISK*. The Journal of Finance, 19(3), 425-442. doi:10.1111/j.15406261.1964.tb02865.x

Treynor, J. L. (1962). Toward a Theory of Market Value of Risky Assets. doi:Available at SSRN: https://ssrn.com/abstract $=628187$ or http://dx.doi.org/10.2139/ssrn.628187 
Treynor, J. L., \& Black, F. (1973). How to Use Security Analysis to Improve Portfolio Selection. Journal of Business, 46, 66-86.

VFF. (2018). Historikk Totalmarkedet (2005-2018). Retrieved from

Yan, X. S. J. J. o. F., \& Analysis, Q. (2008). Liquidity, investment style, and the relation between fund size and fund performance. 43(3), 741-767. 